\title{
GENETICS AND EVOLUTION
}

UNDERSTANDING EVOLUTION. E. Peter Volpe. Wm. C. Brown Company, lowa. Pp. xvi and 160 (Paperback), \$2.25.

The preface of this book states that it is intended " to provide a simple, concise account of the scope and significance of evolution for the college student seeking a liberal education". It begins this task by discussing the distinction between heritable and non-heritable variation. The facts of environmental modification leads to a consideration of the views of Lamarck and Lysenko and thence to Darwin and natural selection.

The second chapter is concerned with the origin of genetic variation and is a brief outline of Mendelian genetics and of the particular importance of mutation and recombination (not neglecting to describe the structure of DNA) in providing the variation on which natural selection can act. The next five chapters provide an elementary but lucid account of population genetics leading up to balanced polymorphisms and random genetic drift. Only one possible mechanism, heterozygote advantage, for the maintenance of a balanced polymorphism is mentioned and, for this reviewer's taste, too much emphasis is placed on the role of drift. But the most serious omissions are of any discussion of the importance of continuously varying characters in the evolution of populations and of a consideration of the concepts of co-adaptation and balanced genotypes and population structure. These omissions make the transition from the section on population genetics to that on the evolution of races and species unnecessarily sudden.

The latter half of the book is concerned with the evolution of separate populations, discussing isolating mechanisms, cataclysmic evolution (changes in ploidy level), adaptive radiation and convergent evolution. It ends with speculative chapters on the origin of life and of man.

Despite its faults this readable and attractively laid out book provides a good introduction to the genetic study of evolution and could be recommended for sixth-form teaching, particularly in the teaching of biology as an "elective" subject if currently suggested reforms for A-level work are accepted.

\author{
K. J. R. EDWARDs \\ Department of Genetics, University of Cambridge
}

\section{THE SUB-DIVISIONS OF HOMO SAPIENS}

THE LIVING RACES OF MAN. Carleton S. Coon. Jonathan Cape. London. 1966. 70 s.

Dr Carleton Coon, at one time best known as the author of a definitive pre-war monograph on The Races of Europe, has, during the past four years, attained a further peak of anthropological prominence mainly as a result of criticism, at times reasoned, at others carping, directed towards a monograph, setting out his views on The Origin of Races. Here, Dr Coon developed the concept that the major geographical groups of extant man had evolved independently and in parallel for a much longer period than is often believed to be the case. As a result, they should, he submitted, properly be regarded as zoological subspecies.

In this earlier monograph, based on an all too limited fossil record, it was further argued that some major geographical subgroups had developed for longer peroids than others - an assertion that led to unfortunate implications 